\title{
Study of epidemiological aspects of hyperuricemia in Poland
}

\author{
Katarzyna Kostka-Jeziorny ${ }^{1}$, Krystyna Widecka ${ }^{2}$, Andrzej Tykarski ${ }^{1}$ \\ ${ }^{1}$ Department of Hypertensiology, Angiology and Internal Diseases, \\ Poznan University of Medical Sciences, Poznan, Poland \\ ${ }^{2}$ Department of Hypertensiology and Internal Diseases, \\ Pomeranian Medical University, Szczecin, Poland \\ This article appeared parallel to the journal \\ Nadciśnienie Tętnicze w Praktyce 2019; 5(1): 1-12 \\ in the Polish language.
}

\begin{abstract}
Background: The results of the latest epidemiological studies show that the problem of hyperuricemia affects many millions of people. The main purpose of the study was to assess the knowledge of physicians with regard to the epidemiology and treatment of hyperuricemia in Poland.

Methods: CAPI (computer assisted personal interview) interviews were conducted using short questionnaires among primary health care physicians, cardiologists and diabetologists. The entire questionnaire included 11 questions. Questions were asked to physicians at 5 different periods in time. The number of physicians surveyed, depended on the time period, and ranged from 8663 to 9980.

Results: Only every 1 in 7 physicians (14\%) considered that hyperuricemia in patients with cardiovascular risk factors begins when the uric acid level is $5 \mathrm{mg} / \mathrm{dL}$, thus in line with the expert recommendations. $72 \%$ of respondents asked to indicate the uric acid levels they consider to be indicative of hyperuricemia in patients in the cardiovascular risk group, gave values ranging from 6 to $7 \mathrm{mg} / \mathrm{dL}$, namely the values justified in cases of a patient without such a risk, i.e. in the general population. $86 \%$ of doctors surveyed gave values different from that recommended by experts.

Conclusions: The findings of the questionnaire in this survey suggests that doctors often underestimate the problem of hyperuricemia in patients with a high risk of cardiovascular disease. An important step towards more effective therapy of hyperuricemia in routine clinical practice is to raise the awareness of hyperuricemia and its comorbidities both among doctors and patients and encourage monitoring and treatment. (Cardiol J 2019; 26, 3: 241-252)
\end{abstract}

Key words: hyperuricemia, arterial hypertension

\section{Introduction}

The results of recent epidemiological studies show that hyperuricemia affects many millions of people [1]. In the coming years, and in connection with an epidemic of obesity, metabolic disorders and an aging population among others factors, a further gradual increase in the incidence of hyperuricemia should be expected $[2,3]$.

Already on the basis of earlier studies, a conclusion was drawn that the relative risk of cardiovascular complications in patients, including

Address for correspondence: Katarzyna Kostka-Jeziorny, MD, PhD, Department of Hypertensiology, Angiology and Internal Diseases, Poznan University of Medical Sciences, ul. Długa 1/2, 61-848 Poznań, Poland, tel: +48 618549182 , fax: +48 6185490 86, e-mail: kostkajeziorny@gmail.com

Received: 20.02.2019 Accepted: 18.04.2019 
Table 1. Questions at 5 periods in time with the following number of participating physicians.

\begin{tabular}{lccccc}
\hline & $\mathbf{1}^{\text {st }}$ period & $\mathbf{2}^{\text {nd }}$ period & $\mathbf{3}^{\text {rd }}$ period & $\mathbf{4}^{\text {th }}$ period & $\mathbf{5}^{\text {th }}$ period \\
\hline $\begin{array}{l}\text { Duration of } \\
\text { the period }\end{array}$ & September - & December 2017 & February - & April - May & June \\
$\begin{array}{l}\text { Number of surveyed } \\
\text { physicians }\end{array}$ & - November 2017 & - January 2018 & - March 2018 & 2018 & 2018 \\
\hline
\end{tabular}

patients with hypertension, increases with a growing level of uric acid in blood serum [4]. However, there was no evidence that hyperuricemia is a factor contributing to the development of cardiovascular disorders, because after considering the other risk factors in statistical analysis, the effect of hyperuricemia seemed to be insignificant [5]. In the recent years, there has been a revival of an interest in uric acid as a prognostic and causative factor in cardiovascular disease (CVD). The analysis of large clinical trials on the relationship between hyperuricemia and the risk of cardiovascular complications in hypertensive patients clearly points to uric acid as an independent predicative factor.

According to the Guidelines of the Polish Society of Arterial Hypertension in 2015, the determination of uric acid concentration is a basic test in patients with hypertension together with a morphology test, glycemia test, determination of sodium and potassium, lipid profile, creatinine, estimated glomerular filtration rate, albuminuria assessment and urinalysis [6]. Also, the latest 2018 European Society of Cardiology/European Society of Hypertension (ESC/ESH) Guidelines for the management of arterial hypertension not only mentions the uric acid test as a basic test, but also considers it to be a factor affecting cardiovascular risk [7].

The definition of hyperuricemia varies widely between publications, which means that epidemiological studies are inconsistent. However, based on the recent studies, analyses and recommendations, physicians should seek to reach and maintain lifelong uric acid levels of $<6 \mathrm{mg} / \mathrm{dL}$ in the general population, and in patients with high cardiovascular risk, the target uric acid level of $5 \mathrm{mg} / \mathrm{dL}$ should be considered [8]. According to the latest Expert Consensus on the diagnosis and treatment of patients with hyperuricemia and high cardiovascular risk, the target uric acid levels of $<5 \mathrm{mg} / \mathrm{dL}$ should be considered in patients with high cardiovascular risk, presenting at least two of the following risk factors: hypertension, diabetes, dyslipidemia, recent stroke or myocardial infarction and chronic kidney disease (CKD) [9].
The main purpose of the study was to assess the knowledge of physicians with regard to the epidemiology and treatment of hyperuricemia in Poland. Research objectives were divided into three groups. The aim of the first group was to assess physician awareness with regard to the incidence of hyperuricemia, and in particular the frequency of ordering appropriate tests and application of therapeutic solutions. The aim of the second group was to identify the actual risk of CVD and metabolic syndrome due to hyperuricemia according to primary health care physicians, cardiologists and diabetologists. An assessment of physician attitudes to the reference values of uric acid concentration levels, screening tests and hyperuricemia therapies available on the market, as well as identification of treatment-related barriers was the goal of the third study group.

\section{Methods}

CAPI (computer assisted personal interview) interviews were conducted using short questionnaires among primary health care physicians, cardiologists and diabetologists. The entire questionnaire included 11 questions. Questions were asked to physicians at 5 different periods (Table 1 ). The number of physicians surveyed, depending on the time period, and ranged from 8663 to 9980. The doctors were asked the following questions:

- Question 1. What concentration of uric acid do you consider to be hyperuricemia in patients at risk of cardiovascular disease?

- Question 2. What diseases are, in your opinion, are most often accompanied by hyperuricemia?

- Question 3. What is the average age of your patients with hyperuricemia $>5 \mathrm{mg} / \mathrm{dL}$ $(298 \mu \mathrm{mol} / \mathrm{L})$ in the cardiovascular risk group?

- Question 4. How often do you order tests to measure uric acid concentration in blood serum for patients with hyperuricemia $>5 \mathrm{mg} / \mathrm{dL}$ $(298 \mu \mathrm{mol} / \mathrm{L})$ in the cardiovascular risk group?

- Question 5. What is the average uric acid concentration of your hyperuricemia patients from the cardiovascular risk group? 


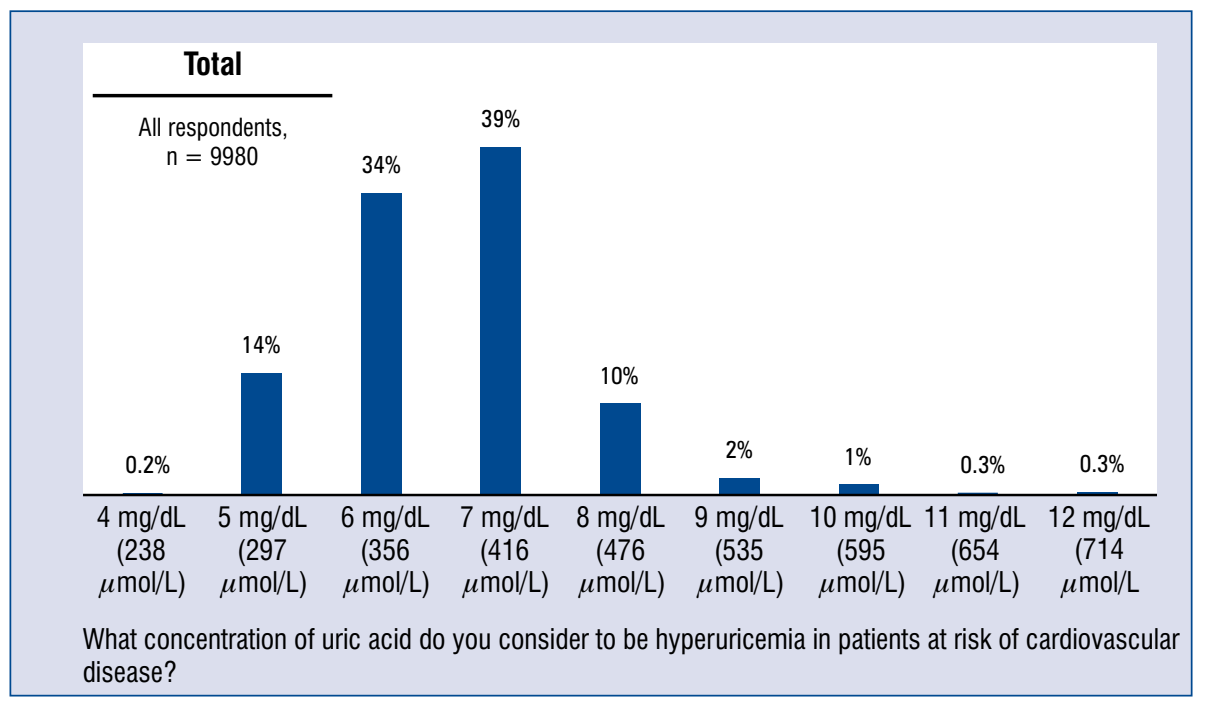

Figure 1. Uric acid reference concentration value considered by physicians as hyperuricaemia at the patients of cardiovascular risk group — distribution of all the responses.

- Question 6. At what concentration of uric acid in a patient at risk of cardiovascular disease do you administer pharmacological treatment of hyperuricemia?

- Question 7. In what percentage of patients from the cardiovascular risk group ( $>5 \mathrm{mg} /$ $/ \mathrm{dL}, 298 \mu \mathrm{mol} / \mathrm{L}$ ) taking medicines to reduce uric acid levels have you decreased the dose of the medicine in the last 3-4 months?

- Question 8. In what percentage of patients from the cardiovascular risk group ( $>5 \mathrm{mg} / \mathrm{dl}$, $298 \mu \mathrm{mol} / \mathrm{L}$ ) taking medicines aimed to reduce uric acid levels have you increased the dose of the medicine in the last 3-4 months?

- Question 9. In your opinion, how long should be the pharmacological treatment of hyperuricaemia last in patients with cardiovascular risk (> $5 \mathrm{mg} / \mathrm{dL}, 298 \mu \mathrm{mol} / \mathrm{L})$ ?

- Question 10. From your observations, what are the effects on hyperuricemia on cardiovascular risk ( $>5 \mathrm{mg} / \mathrm{dL}, 298 \mu \mathrm{mol} / \mathrm{L})$ ?

- Question 11. Have you noticed an increase in the incidence of hyperuricemia in patients with cardiovascular risk ( $>5 \mathrm{mg} / \mathrm{dL}, 298 \mu \mathrm{mol} / \mathrm{L}$ ) over the past 2 years?

The study was performed over a period from September 2017 to June 2018. Questions were asked at 5 periods with the following number of participating physicians (Table 1).

\section{Results}

Only every 1 in 7 physicians (14\%) considers that hyperuricemia in patients with cardiovascular risk factors begins when the uric acid level is $5 \mathrm{mg} /$ $/ \mathrm{dL}$, thus in line with the expert recommendations $[8,9] .72 \%$ of respondents asked to indicate the uric acid levels they consider to be indicative of hyperuricemia in patients in the cardiovascular risk group gave values ranging from 6 to $7 \mathrm{mg} / \mathrm{dL}$, namely the values justified in cases of patients without such a risk, i.e. in the general population. $86 \%$ of doctors surveyed gave values different from that recommended by experts, namely other than $5 \mathrm{mg} / \mathrm{dL}$, as the reference value of hyperuricemia in patients presenting with cardiovascular risk factors (Fig. 1).

In answer to the question of what diseases, according to them, most often accompany hyperuricemia, physicians indicated the most often hypertension (91\%), metabolic syndrome (89\%) and diabetes (84\%) (Fig. 2).

According to the doctors surveyed, the average age of patients with hyperuricemia $>5 \mathrm{mg} / \mathrm{dL}$ $(298 \mu \mathrm{mol} / \mathrm{L})$ in the cardiovascular risk group was 55 years. Nearly $1 / 3$ doctors had declared that the average age of their patients with hyperuricemia $>5 \mathrm{mg} / \mathrm{dL}(298 \mu \mathrm{mol} / \mathrm{L})$ in the cardiovascular risk group was 50 years or less, and the next one third of doctors indicated that the age was 60 years or more (Fig. 3).

Almost half of the doctors (48\%) order a test of uric acid concentration in blood serum once a year in patients with hyperuricemia $>5 \mathrm{mg} / \mathrm{dL}$ $(298 \mu \mathrm{mol} / \mathrm{L})$ in the cardiovascular risk group, and more than $1 / 3$ of physicians $(38 \%)$ order the test twice a year (Fig. 4).

Average concentration levels of uric acid in patients with hyperuricemia $>5 \mathrm{mg} / \mathrm{dL}$ 


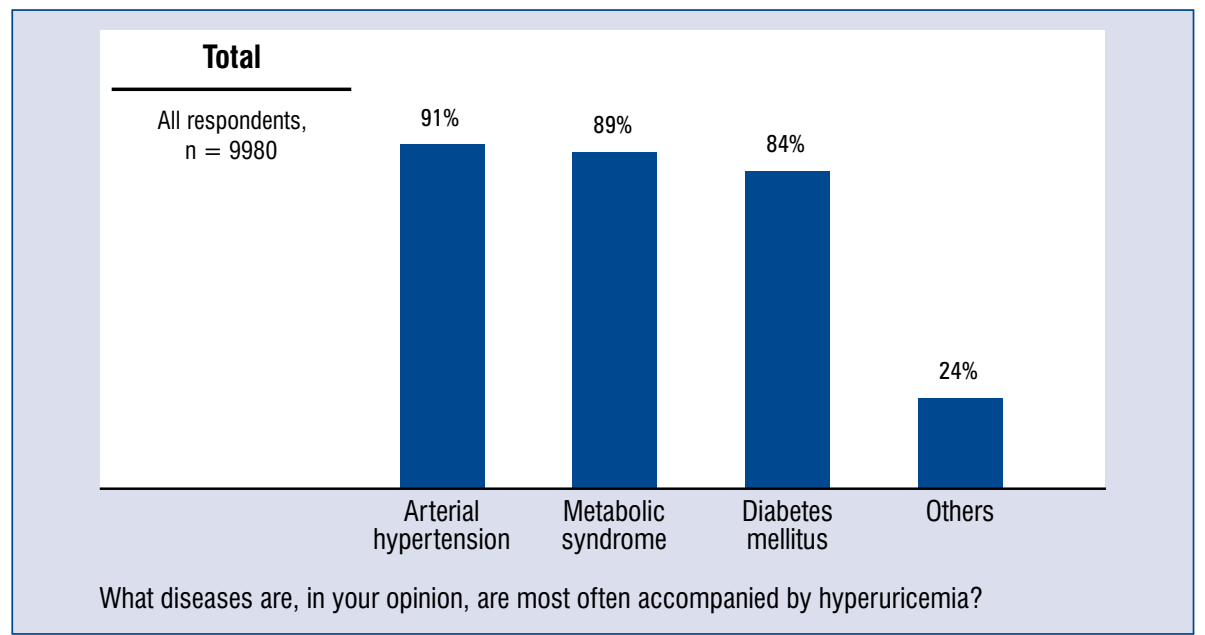

Figure 2. Diseases usually accompanied by hyperuricaemia - distribution of responses.

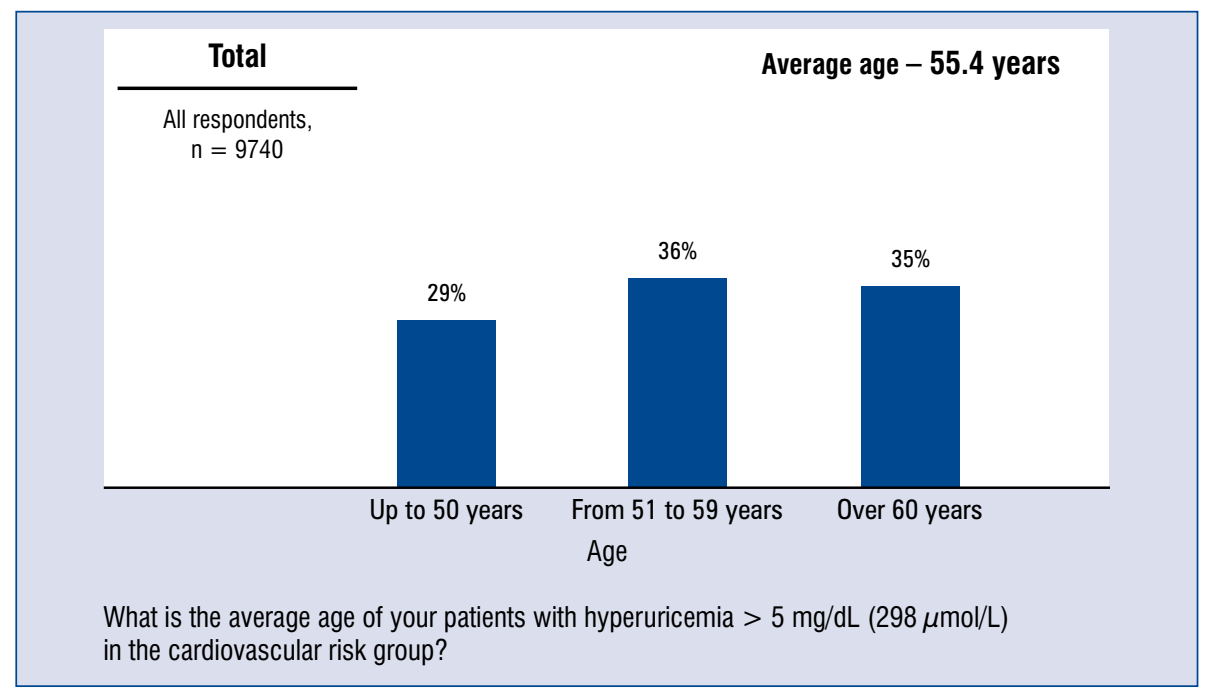

Figure 3. Average age of patients with hyperuricaemia $>5 \mathrm{mg} / \mathrm{dL}(298 \mu \mathrm{mol} / \mathrm{L})$ of the cardiovascular risk group distribution of responses and average.

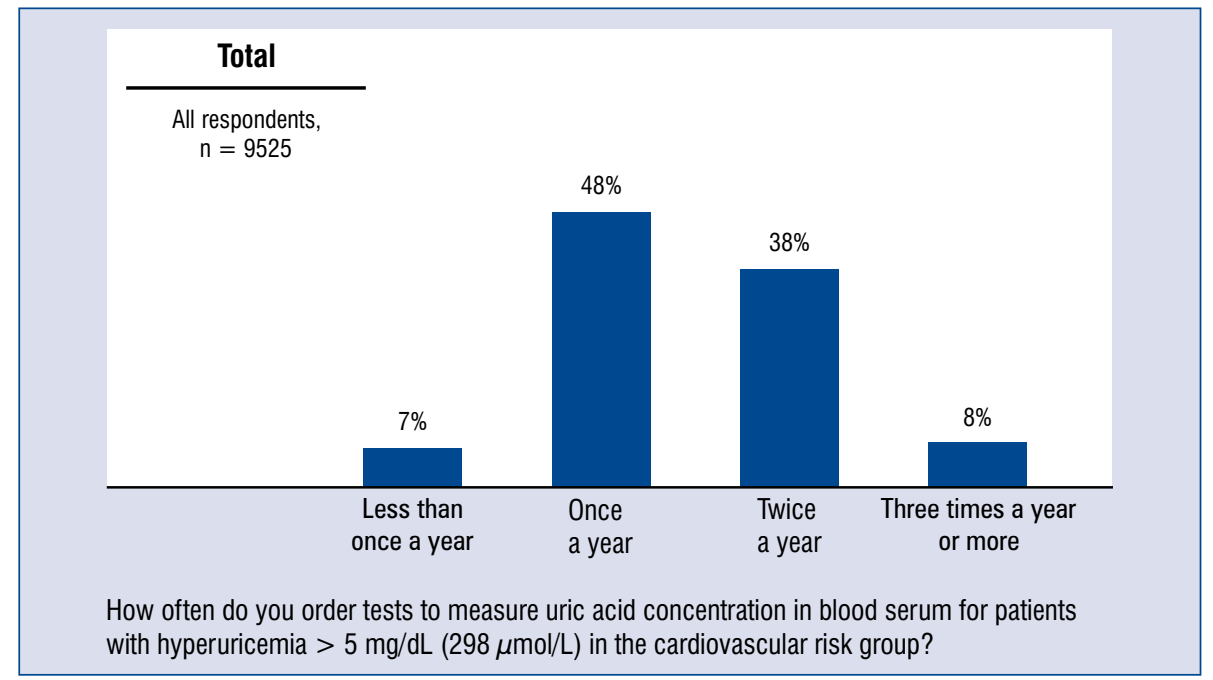

Figure 4. Frequency of ordering urea acid tests in serum at patients with hyperuricaemia $>5 \mathrm{mg} / \mathrm{dL}$ (298 $\mu \mathrm{mol} / \mathrm{L})$ of the cardiovascular risk group - distribution of responses. 


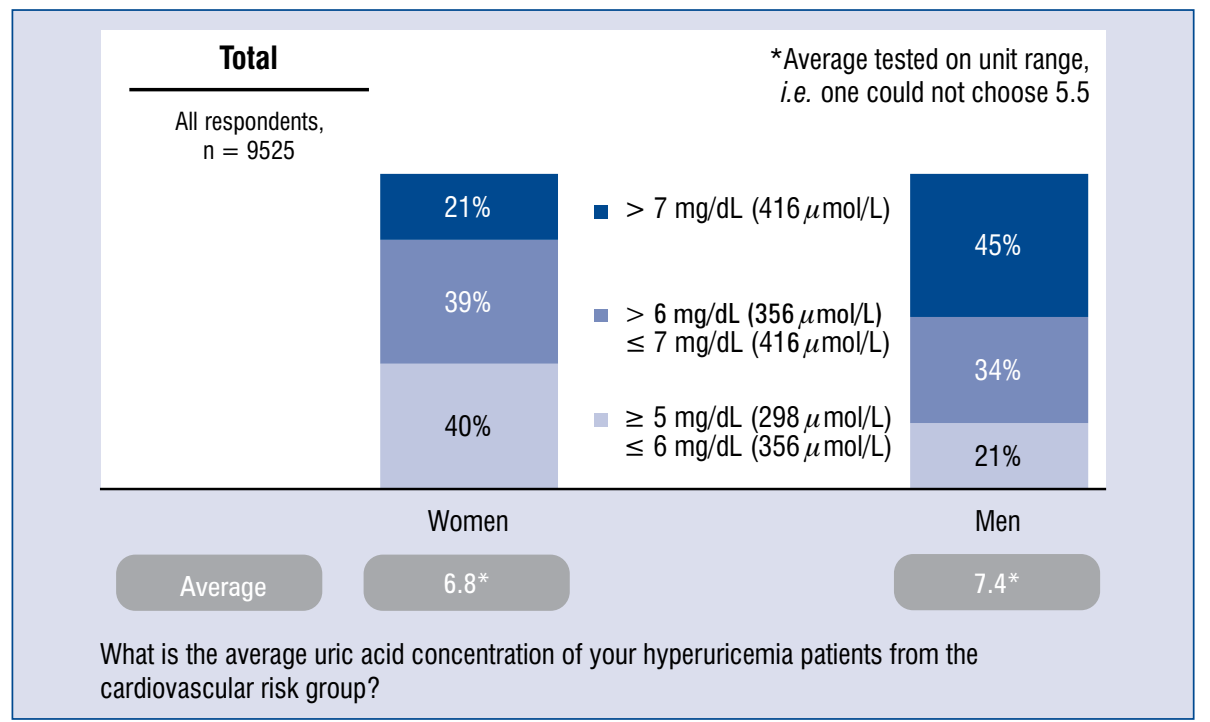

Figure 5. Average concentration of uric acid at patients with hyperuricemia $>5 \mathrm{mg} / \mathrm{dL}$ ( $298 \mu \mathrm{mol} / \mathrm{L}$ ) of the cardiovascular risk group — distribution of responses and average.

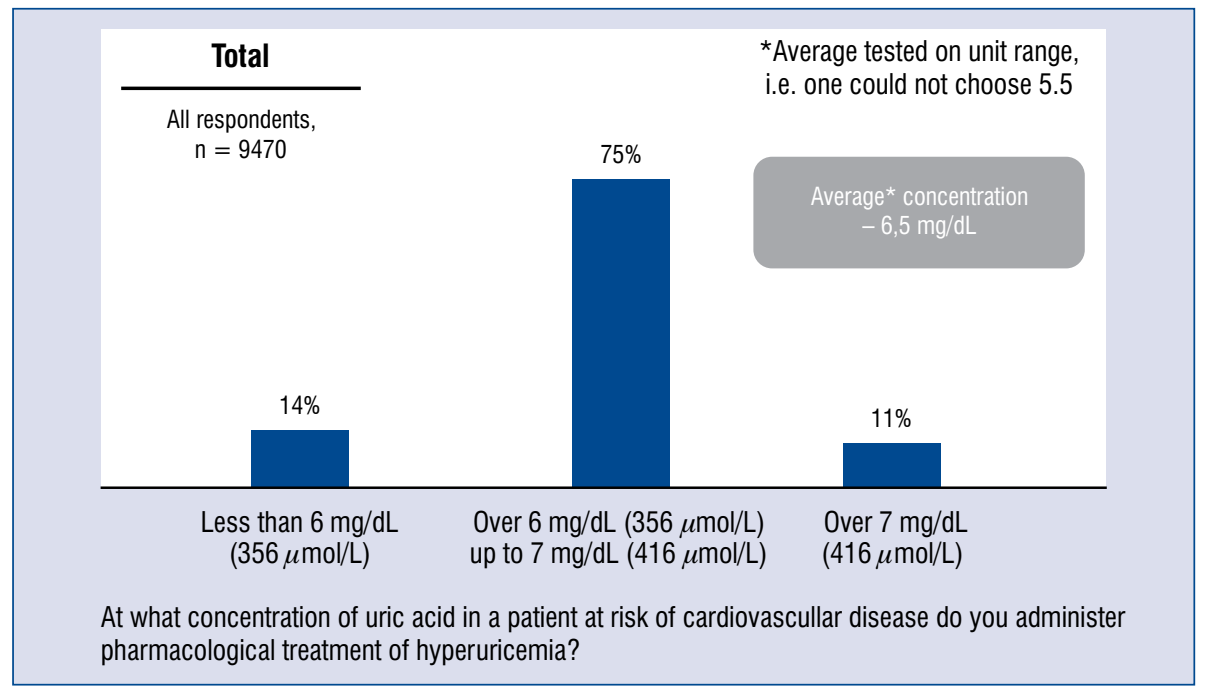

Figure 6. Uric acid concentration value at which the physician includes pharmacologic treatment of hyperuricemia for patients of the cardiovascular risk group - aggregated distribution of responses and average.

( $298 \mu \mathrm{mol} / \mathrm{L})$ in the cardiovascular risk group is higher among men than among women. It is on average $6.8 \mathrm{mg} / \mathrm{dL}$ in female patients and $7.4 \mathrm{mg} / \mathrm{dL}$ in male patients (Fig. 5).

The vast majority of doctors, namely $75 \%$ of respondents commence pharmacological treatment of hyperuricemia in a patient at risk of CVD, when the concentration of uric acid is between 6 and $7 \mathrm{mg} / \mathrm{dL}, 14 \%$ - when this concentration is lower than $6 \mathrm{mg} / \mathrm{dL}$, and another $11 \%$ - when it is above $7 \mathrm{mg} / \mathrm{dL}$ (Fig. 6).

Physicians generally do not reduce the dose of medicine that lowers uric acid concentration in patients with hyperuricemia in the cardiovascular risk group. $72 \%$ of physicians had not reduced the dose of medicines in their patients in the prior 3-4 months. The average percentage of patients with hyperuricemia in the cardiovascular risk group, from doctors who had reduced the dose of medicine which reduces uric acid concentration was $14 \%$ (taking into account only doctors had reduced dosage). Almost all doctors increased the doses of medicine reducing uric acid concentration in patients with hyperuricemia in the cardiovascular risk group - only $2 \%$ of physicians over the prior 3-4 months did not have this type of patient. 


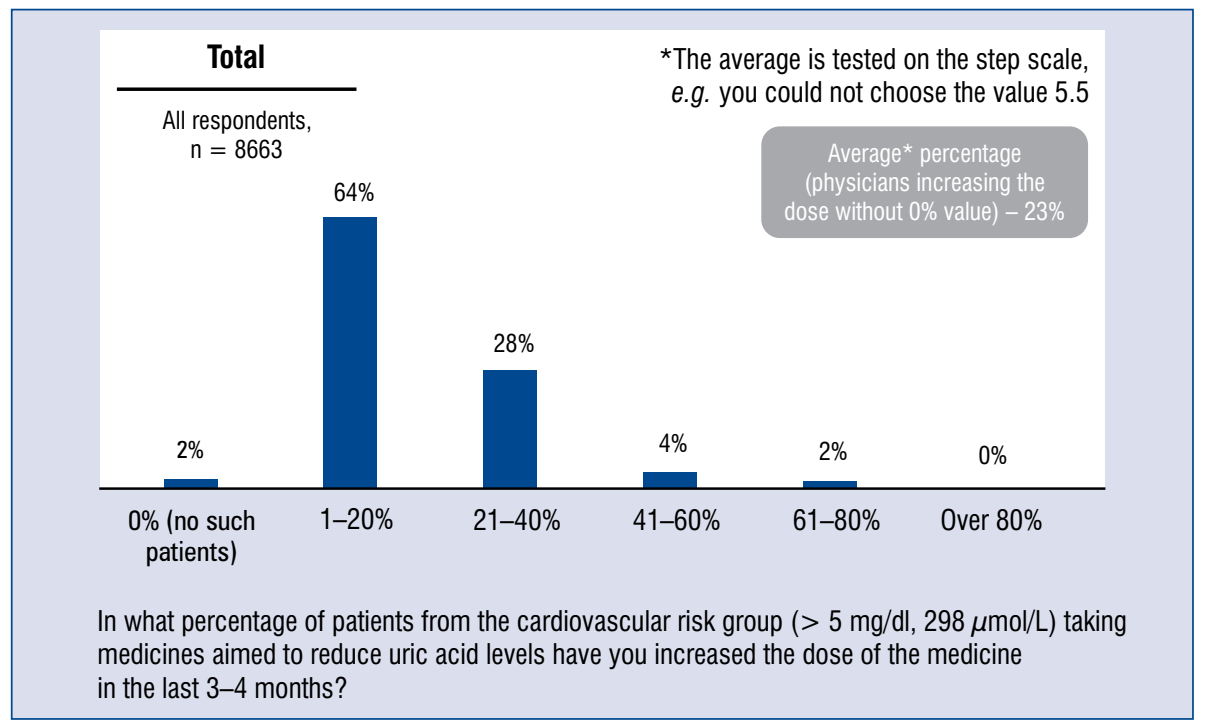

Figure 7. Percentage of patients with hyperuricemia $>5 \mathrm{mg} / \mathrm{dL}(298 \mu \mathrm{mol} / \mathrm{L})$ in the cardiovascular risk group taking medicines lowering uric acid concentration, whose doctor had increased the dose in the prior 3-4 months - aggregated distribution of responses and the average.

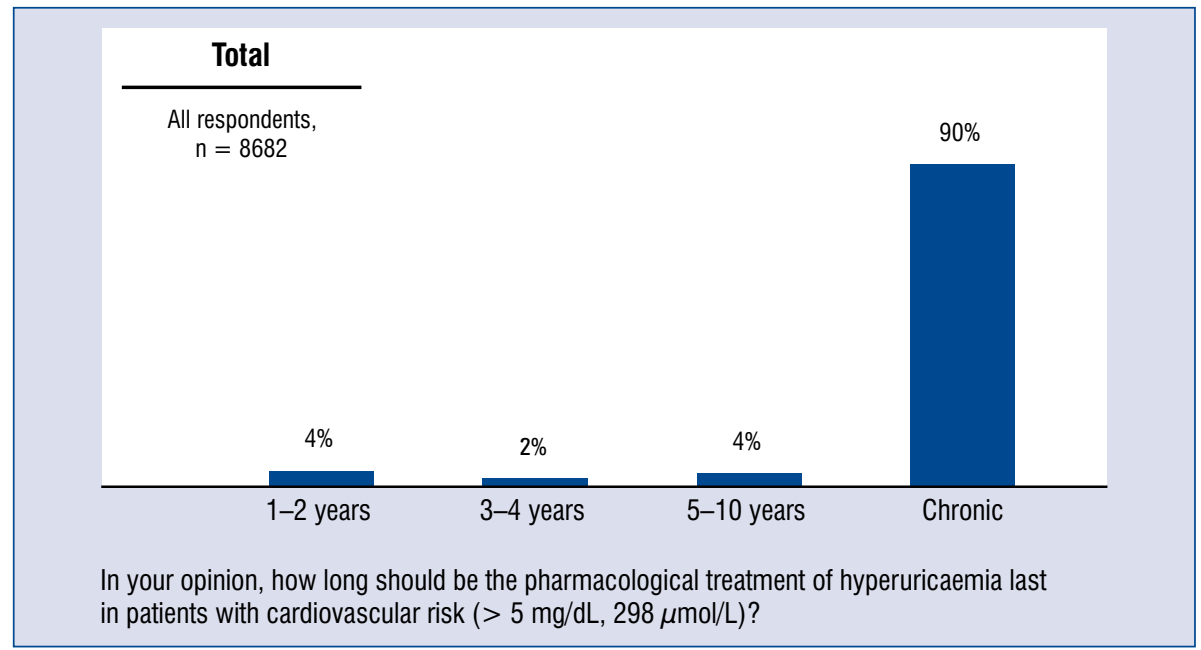

Figure 8. The assumed length of pharmacological treatment of hyperuricemia for patients in the cardiovascular risk group ( $>5 \mathrm{mg} / \mathrm{dL} ; 298 \mu \mathrm{mol} / \mathrm{l}$ ) — distribution of responses.

The average percentage of patients with hyperuricemia in the cardiovascular risk group, in cases of doctors who had increased the dose of drugs that lower medicines reducing uric acid concentration is $23 \%$ (includes only dose-increasing doctors) (Fig. 7).

$90 \%$ of doctors believe that pharmacological treatment of hyperuricemia in patients in the cardiovascular risk group should be included permanently (Fig. 8).

Nearly $80 \%$ of respondents believe that hyperuricemia ( $>5 \mathrm{mg} / \mathrm{dL} ; 298 \mu \mathrm{mol} / \mathrm{L}$ ) has a high impact on cardiovascular risk. The remaining $20 \%$ of doctors believed that the effect of hyperuricemia on cardiovascular risk is moderate (Fig. 9). Moreover, $91 \%$ doctors have observed an increase in the occurrence of hyperuricemia over the prior 2 years in patients from the cardiovascular risk group (Fig. 10).

\section{Discussion}

Based on available research and recommendations, the target uric acid concentration of $<5 \mathrm{mg} / \mathrm{dL}$ 


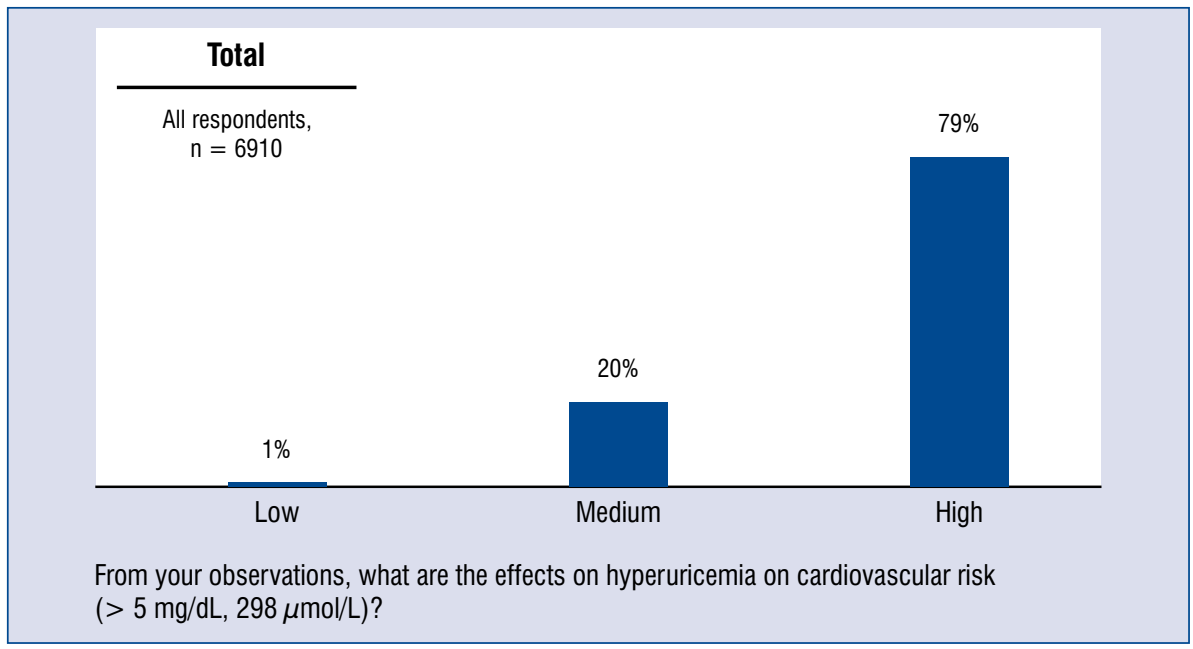

Figure 9. Assessment of the impact of hyperuricemia ( $>5 \mathrm{mg} / \mathrm{dL}, 298 \mu \mathrm{mol} / \mathrm{L}$ ) on cardiovascular risk — distribution of responses.

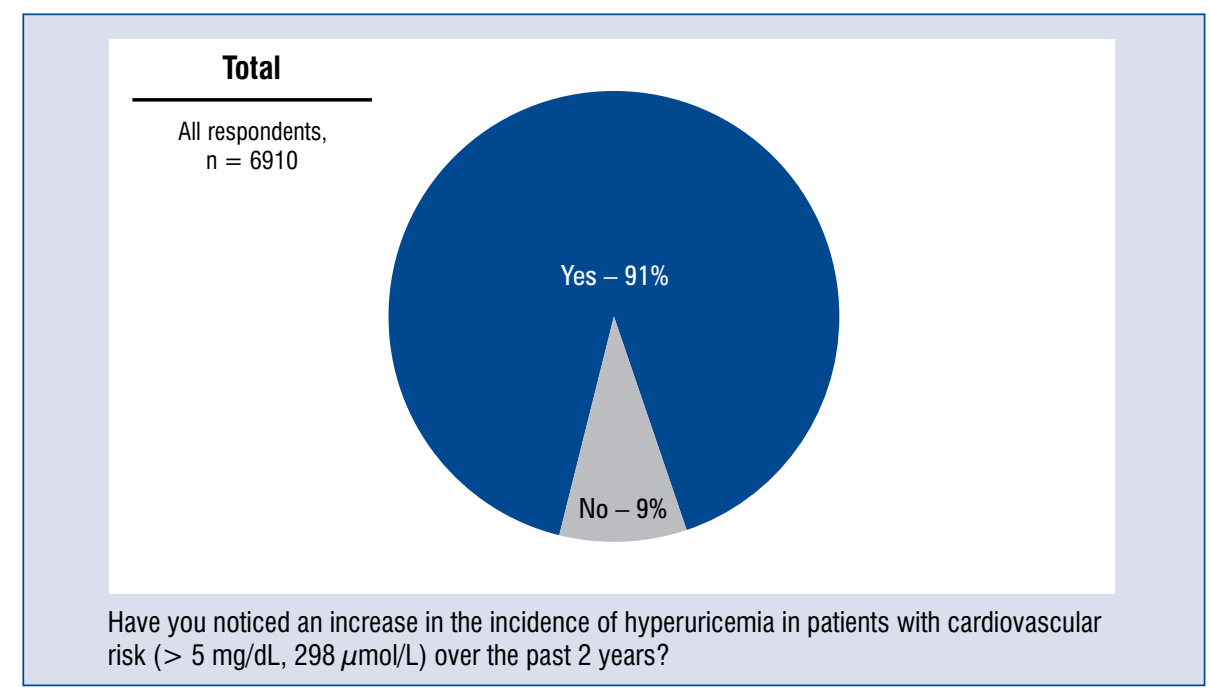

Figure 10. Frequency of hyperuricemia for patients in the cardiovascular risk group (> $5 \mathrm{mg} / \mathrm{dL} ; 298 \mu \mathrm{mol} / \mathrm{L}$ ) within the prior 2 years - distribution of responses.

should be considered in patients with high cardiovascular risk. High cardiovascular risk patients are considered to be those persons with hypertension, diabetes, metabolic syndrome, diagnosed atherosclerosis of any vascular bed (including patients with coronary artery disease [CAD] or atherosclerotic cerebrovascular disease) [8]. According to the position of international experts, the target uric acid concentration of $<5 \mathrm{mg} / \mathrm{dL}$ should be considered in patients with high cardiovascular risk, presenting with at least two of the following factors: hypertension, diabetes, dyslipidaemia, recent stroke or myocardial infarction, CKD [9].
It should be noted that the PAMELA study confirmed the benefits of maintaining a level of approximately $5 \mathrm{mg} / \mathrm{dL}$ in patients with high cardiovascular risk [10]. In the present study, patients were randomly recruited from the general population and subjected to a detailed assessment of the cardiovascular risk profile. Echocardiography and blood pressure measurements were also performed other than at the doctor's office. Data analysis suggests the limit value of uric acid concentration of $5.4 \mathrm{mg} / \mathrm{dL}$, providing the best sensitivity ratio to the specificity of the study in predicting the risk of cardiovascular mortality and $4.9 \mathrm{mg} / \mathrm{dL}$ for total mortality. 
The findings of the current study show that relatively few doctors are aware of the recommendations related to the treatment of hyperuricemia in patients with high cardiovascular risk. Only $14 \%$ of doctors ( 1 in 7 respondents) indicate the value recommended by experts, and $3 / 4(72 \%)$ of respondents asked to indicate uric acid levels they considered to be hyperuricemia in patients from the cardiovascular risk group, indicate values ranging from 6 to $7 \mathrm{mg} / \mathrm{dL}$, i.e. the value justified in patients without such a risk. Yet, it should not be surprising that doctor responses may have been influenced by the many years of definitions of hyperuricemia, which have differed significantly between publications, i.e. epidemiological studies were inconsistent. Hyperuricemia used to be considered present when uric acid concentration in blood serum exceeded $7 \mathrm{mg} / \mathrm{dL}$ in male patients and $6 \mathrm{mg} / \mathrm{dL}$ in female patients. According to another definition hyperuricemia was defined as values above $6.4-6.8 \mathrm{mg} / \mathrm{dL}$, at $37^{\circ} \mathrm{C}$, being the total saturation of the plasma with sodium urate takes place [11]. Therefore, it still seems necessary to educate the medical community with regards to the definition of the value of hyperuricemia in patients with high cardiovascular risk.

Uric acid is recognized as an independent risk factor in the development of many macrovascular and microvascular disorders, including arterial hypertension [12], metabolic syndrome [13, 14], CAD [15], diabetes [16], cerebrovascular disease [17, 18], CKD [19] or other CVD [20, 21]. When asked what diseases, in their opinion, are most often associated with hyperuricemia, the respondents listed the following: hypertension (91\%), metabolic syndrome $(89 \%)$ and diabetes $(84 \%)$. An increased concentration of uric acid impairs oxygen metabolism, stimulates the renin-angiotensin system and inhibits the secretion of endothelial nitric oxide. Therefore, it contributes to the development of microvascular complications in arterioles vasoconstriction, renal vasoconstriction, and persistent sodium chloride hypertension [22, 23]. As evidenced, most physicians are aware of the relationship between the increase in a relative risk of hypertension and high levels of uric acid [24, 25]. Most also know the relationship between hyperuricemia and metabolic syndrome. Diabetes as a disease often accompanying hyperuricemia is also indicated much less frequently - by 8 out of 10 doctors. It seems that respondents have the knowledge that elevated uric acid is the result of a diet which is rich in purine/fructose, genetic and environmental factors, metabolic disorders as well as endogenous overproduction or, in most cases, im- paired excretion of uric acid. Pre-clinical test results suggest that endothelial dysfunction, inflammatory reaction and oxidative stress in fat cells play a key role in the development of metabolic syndrome [26]. Some studies describe the relationship between uricemia and obesity, between uricemia and obesity and insulin resistance. Therefore, uric acid was suggested as a component of the metabolic syndrome [27].

Yet, what was surprising was the lack of awareness of the doctors surveyed, of the relationship between hyperuricaemia and ischemic heart disease, and thus a growing cardiovascular risk. Oxidative stress caused by increased xanthine oxidase activity has a very negative effect on the endothelium vascular system, including coronary arteries $[28$, 29]. Based on data from the NHANES I study (First National Health and Nutrition Examination Study), Freedman et al. [1] proved that any increase in the value of uric acid concentration by $60 \mu \mathrm{mol} / \mathrm{L}$ is linked with a $48 \%$ increase in the risk of ischemic heart disease in women. In patients demonstrating cardiovascular complications (with angiographically diagnosed $\mathrm{CAD}$, after ischemic stroke, with chronic heart failure) it has been shown that uric acid concentration is an independent prognostic factor for general and cardiovascular mortality of patients [30-32].

Moreover, the surveyed doctors do not mention the correlation of hyperuricemia with CKD, and high levels of uric acid, which indeed play a key role in the development and progression of CKD. It also remains an independent factor in the progression of CKD, even after adjustment for all classical co-existing diseases, such as hypertension, proteinuria and dyslipidaemia. This relationship was confirmed in patients with IgA nephropathy, diabetic nephropathy, after organ transplantation and in autosomal dominant polycystic kidney disease.

Almost $1 / 3$ of physicians declared that the average age of their patients with hyperuricemia $>5 \mathrm{mg} / \mathrm{dL}(298 \mu \mathrm{mol} / \mathrm{L})$ in the cardiovascular risk group was 50 years or less, and another $1 / 3$ declared that their age was 60 years or more. The prevalence hyperuricemia depends on the sex, age and race and reaches its peak in people at around the age of 70 . In young and healthy people, before puberty, it is low and usually does not exceed $3.6 \mathrm{mg} / \mathrm{dL}$. In men, it is on average $5 \pm 2 \mathrm{mg} / \mathrm{dL}$, and in women at childbearing age it is on average $1 \mathrm{mg} / \mathrm{dL}$ lower, and increases after menopause (the role of oestrogen). Yet, it should be remembered that the elevated concentration of uric acid is observed in almost $90 \%$ of adolescents with primary hypertension [33]. 
Almost half of physicians in the present study check serum uric acid concentration once a year in patients with hyperuricemia $>5 \mathrm{mg} / \mathrm{dL}$ $(298 \mu \mathrm{mol} / \mathrm{L})$ in the cardiovascular risk group and $38 \%$ of physicians will order the test for their patients twice a year. In patients in whom are introduced a hyperendemic agent, urine acid concentration should be controlled every 4 weeks after each increase of the dose until a therapeutic goal is achieved. According to the recommendations, after a therapeutic goal is achieved the dose of a drug reducing uric acid concentration (in practice, allopurinol) should be maintained, and uric acid concentration should be monitored periodically, twice a year.

The vast majority of doctors, namely $3 / 4$ of respondents start pharmacological treatment of hyperuricemia in patients at risk of CVD only when the concentration of uric acid is between 6 and $7 \mathrm{mg} / \mathrm{dL}, 14 \%$ - when the concentration is lower than $6 \mathrm{mg} / \mathrm{dL}$, and another $11 \%$ - when it is above $7 \mathrm{mg} / \mathrm{dL}$. Once again one should be reminded that based on the current knowledge of physicians, they consider treatment with allopurinol when the level of uric acid is above $5 \mathrm{mg} / \mathrm{dL}$ in patients with high cardiovascular risk, presenting at least two of the following conditions: hypertension, diabetes, dyslipidaemia, recent stroke or myocardial infarction or CKD.

The international consensus on hyperuricemia in patients with high cardiovascular risk suggests that physicians should consider administering an initial dose of allopurinol of $100 \mathrm{mg}$ daily, and gradually increase it to $300-600 \mathrm{mg}$ per day, until the target concentration of uric acid is reached $[9,34]$. A slow increase in the dose of allopurinol has resulted from the need to minimize the likelihood of an incidence of side effects, especially in patients with hypersensitivity to allopurinol or severe cutaneous allergic reactions (SCARs), which usually occurs after 8 weeks of the treatment [35-37]. There are several factors that especially contributed to the development of this syndrome, such as high initial doses, CKD, parallel use of diuretics or the presence of HLA-B*5801 [38, 39]. Almost all doctors surveyed in the study declared that they increased doses of uric acid-lowering drugs in patients with hyperuricemia in the cardiovascular risk group - only $2 \%$ of physicians over the prior 3-4 months did not have such patients. The average percentage of patients with hyperuricemia from the cardiovascular risk groups in which doctors increase the dose of medicine lowering uric acid levels is $23 \%$ (taking into account only doctors who increase the dose).
Allopurinol therapy in patients with high cardiovascular risk is a chronic treatment. $90 \%$ of the respondents gave such a response. Nearly $80 \%$ of physicians believe that hyperuricemia ( $>5 \mathrm{mg} / \mathrm{dL}$, $298 \mu \mathrm{mol} / \mathrm{L}$ ) considerably affects cardiovascular risk. The remaining $20 \%$ of doctors believe that the impact of hyperuricemia on cardiovascular risk is moderate. Hyperuricemia plays an important pathophysiological role in the development of hypertension, type 2 diabetes and is an independent cardiovascular risk factor.

Important data confirming the predictive value of uric acid concentrations were obtained based from observations of the original Framingham heart study cohort. Thus, the study showed an increased risk of ischemic disease and myocardial infarction in patients with high levels of uric acid in serum. Krishnan et al. [40] confirmed the independent effect of uric acid on the risk of acute myocardial infarction. In the Rotterdam Study $(\mathrm{n}=4385)$ in patients without a history of myocardial infarction or stroke at the beginning of the study, high uric acid concentrations were associated with a distant risk of myocardial infarction and stroke [41]. In a study by Ndrepepa et al. [42] the total of 5124 patients with acute coronary syndromes (1629 myocardial infarction with ST segment elevation, 1332 myocardial infarction without ST segment elevation and 2163 with unstable angina) were divided into quartiles according to uric acid concentration levels as follows: quartile 1: $1.3-5.3 \mathrm{mg} / \mathrm{dL}(77-315$ $\mu \mathrm{mol} / \mathrm{L})$; quartile 2: $5.3-6.3 \mathrm{mg} / \mathrm{dL}(315-375 \mu \mathrm{mol} / \mathrm{L})$; quartile 3: $6.3-7.5 \mathrm{mg} / \mathrm{dL}(375-446 \mu \mathrm{mol} / \mathrm{L})$; quartile 4: $7.5-18.4 \mathrm{mg} / \mathrm{dL}(446-1094 \mu \mathrm{mol} / \mathrm{L})$. After 1 year of observations there were 80 deaths in quartile 1 , 77 deaths in quartile 2,72 deaths in quartile 3 , and 221 deaths in the quartile 4 of uric acid concentrations. The unadjusted mortality risk ratio was 3.05 (95\% confidence interval 2.54-3.67, $\mathrm{p}<0.001$ ) for the quartile 4 vs. quartile 1 of these concentrations. It should be noted that after taking into account the traditional cardiovascular risk factors, renal functions and inflammation, the relationship between uric acid concentration and mortality remained significant.

$91 \%$ of the physicians surveyed had seen an increase in the incidence of hyperuricemia in patients at risk of CVD over the prior 2 years. The trend observed by doctors is correct. In the coming years, due to the epidemic of obesity, metabolic disorders and an aging population, the incidence of hyperuricemia will continue to be observed. It is also related to rapid economic development and a changing lifestyle of societies which enjoy a higher social and economic status. Rising uric acid levels also result from the adoption of a Western 


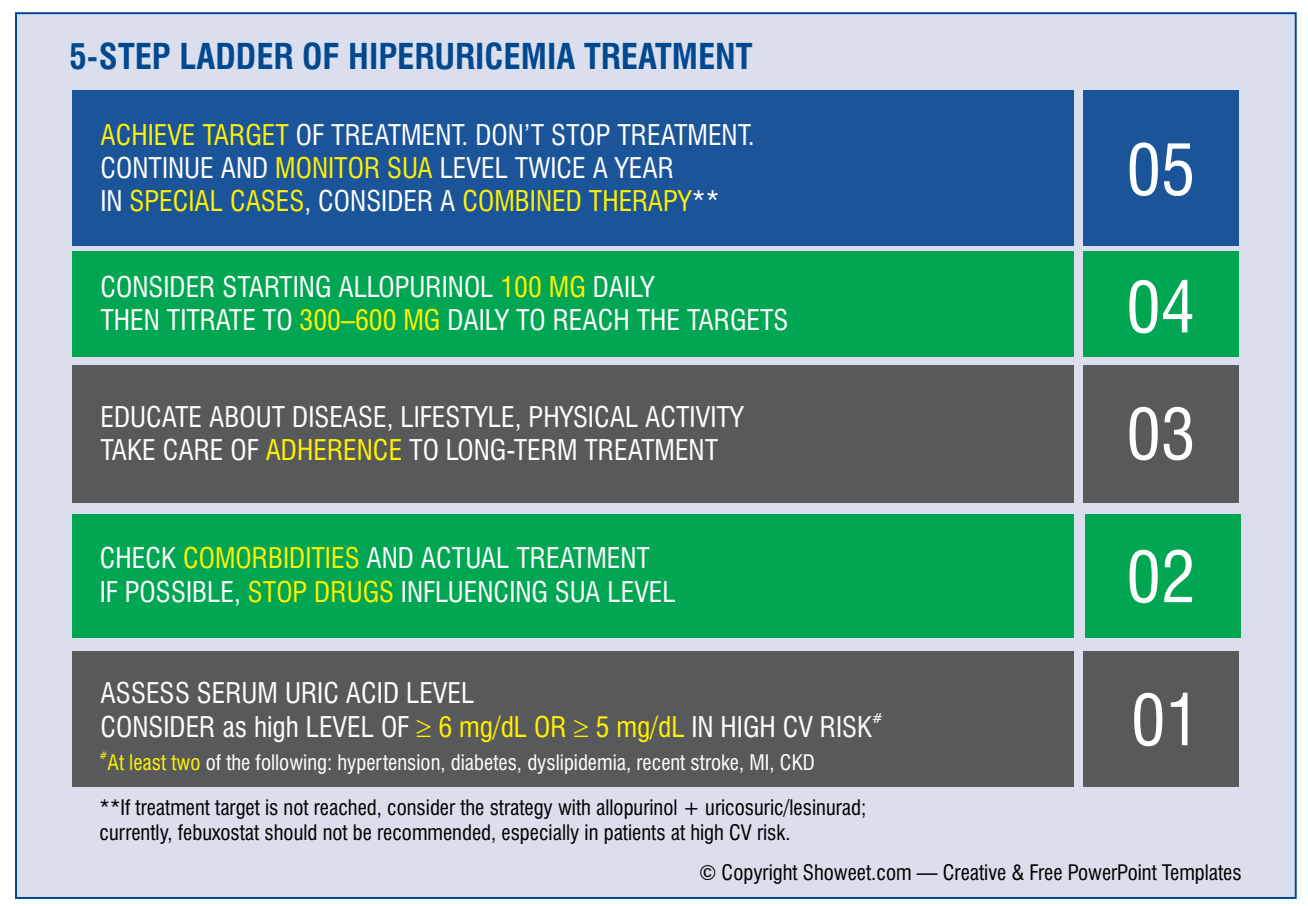

Figure 11. Management strategy for patients suffering from hyperuricemia [9]; CV — cardiovascular; CKD — chronic kidney disease; MI - myocardial infarction; SUA — serum uric acid.

lifestyle and changing economic status. Increased morbidity from hyperuricemia is also favoured by such commonly adopted habits as excessive consumption of products rich in purines (meat, offal), fructose, glucose and fructose syrup or alcohol.

\section{Conclusions}

The findings of the questionnaire in the present survey suggest that doctors often underestimate the problem of hyperuricemia in patients with high risk of CVD. An important step towards more effective therapy of hyperuricemia in routine clinical practice will be to raise the awareness of hyperuricemia and comorbidities both among doctors and patients and encourage their monitoring and treatment. Patients should be educated on the impact some foods on the development of uricemia: high consumption red meat and seafood, alcohol, fructose and sweetened beverages. Research has also confirmed that weight loss and regular physical activity should be highly recommended.

The dissemination of information about the new norm for uricemia in high-risk cardiovascular patients was largely supported by the introduction of an appropriate legend containing information about standards for different patient populations in the results of tests conducted by the majority of large medical laboratories.
Introduction of explanatory information, as was previously the case in the lipid profile (different purpose of therapy depending on cardiovascular risk), will certainly help to raise awareness of hyperuricemia in cardiac patients and achieving therapeutic goals.

Allopurinol should be the first-line treatment of hyperuricemia. An initial dose of $100 \mathrm{mg}$ of allopurinol daily should be considered. The dose should gradually be increased to $300-600 \mathrm{mg}$ per day until reaching the goal conforming to the target uric acid concentration. In cases where a therapeutic goal cannot be achieved; the treatment should be changed to a more complex therapy.

The international consensus on the treatment of patients with hyperuricemia and high cardiovascular risk, suggests a simple 5-step scheme (Fig. 11 [9]). This scheme should considered a sort of road map for doctors in the treatment of patients with high cardiovascular risk with co-occurring hyperuricemia.

\section{Conflict of interest: None declared}

\section{References}

1. Freedman DS, Williamson DF, Gunter EW, et al. Relation of serum uric acid to mortality and ischemic heart disease. The NHANES I Epidemiologic Follow-up Study. Am J Epidemiol. 1995; 141(7): 637-644, indexed in Pubmed: 7702038. 
2. Smith E, Hoy D, Cross M, et al. The global burden of gout: estimates from the Global Burden of Disease 2010 study. Ann Rheum Dis. 2014; 73(8): 1470-1476, doi: 10.1136/annrheumdis-2013-204647, indexed in Pubmed: 24590182.

3. Roddy E, Choi HK. Epidemiology of gout. Rheum Dis Clin North Am. 2014; 40(2): 155-175, doi: 10.1016/j.rdc.2014.01.001, indexed in Pubmed: 24703341.

4. Culleton B, Larson M, Kannel W, et al. Serum Uric Acid and Risk for Cardiovascular Disease and Death: The Framingham Heart Study. Ann Intern Med. 1999; 131(1): 7-13, doi: 10.7326/00034819-131-1-199907060-00003.

5. Ostrander LD, Lamphiear DE. Coronary risk factors in a community. Findings in Tecumseh, Michigan. Circulation. 1976; 53(1): 152-156, doi: 10.1161/01.cir.53.1.152, indexed in Pubmed: 1244237 .

6. Tykarski A, Narkiewicz K, Gaciong Z, et al. 2015 guidelines for the management of hypertension. Recommendations of the Polish Society of Hypertension — short version. Kardiol Pol. 2015; 73(8): 676-700, doi: 10.5603/KP.2015.0157, indexed in Pubmed: 26304155.

7. Williams B, Mancia G, Spiering W, et al. 2018 ESC/ESH Guidelines for the management of arterial hypertension. Eur Heart J. 2018; 39(33): 3021-3104, doi: 10.1093/eurheartj/ehy339, indexed in Pubmed: 30165516.

8. Widecka K, Szymański FM, Filipiak KJ, et al. Stanowisko ekspertów dotyczące hiperurykemii i jej leczenia u pacjentów z wysokim ryzykiem sercowo-naczyniowym. Arterial Hypertens. 2017; 21(1): 1-9, doi: 10.5603/AH.2017.0001, indexed in Pubmed: 30394510.

9. Borghi C, Tykarski A, Widecka K, et al. Expert consensus for the diagnosis and treatment of patient with hyperuricemia and high cardiovascular risk. Cardiol J. 2018; 25(5): 545-563, doi: 10.5603/ CJ.2018.0116, indexed in Pubmed: 30394510.

10. Bombelli M, Toso E, Peronio M, et al. The Pamela study: main findings and perspectives. Curr Hypertens Rep. 2013; 15(3): 238-243, doi: 10.1007/s11906-013-0348-1, indexed in Pubmed: 23609611.

11. Beck L. Clinical disorders of uric acid metabolism. Med Clin North Am. 1981; 65(2): 401-411, doi: 10.1016/s00257125(16)31531-0, indexed in Pubmed: 6894473.

12. Cannon PJ, Stason WB, Demartini FE, et al. Hyperuricemia in primary and renal hypertension. N Engl J Med. 1966; 275(9): 457-464, doi: 10.1056/NEJM196609012750902, indexed in Pubmed: 5917940.

13. Ford ES, Li C, Cook S, et al. Serum concentrations of uric acid and the metabolic syndrome among US children and adolescents. Circulation. 2007; 115(19): 2526-2532, doi: 10.1161/CIRCULATIONAHA.106.657627, indexed in Pubmed: 17470699.

14. Puig JG, Martínez MA. Hyperuricemia, gout and the metabolic syndrome. Curr Opin Rheumatol. 2008; 20(2): 187-191, doi: 10.1097/BOR.0b013e3282f4b1ed, indexed in Pubmed: 18349749 .

15. Tuttle KR, Short RA, Johnson RJ. Sex differences in uric acid and risk factors for coronary artery disease. Am J Cardiol. 2001; 87(12): 1411-1414, indexed in Pubmed: 11397367.

16. Dehghan A, van Hoek M, Sijbrands EJG, et al. High serum uric acid as a novel risk factor for type 2 diabetes. Diabetes Care. 2008; 31(2): 361-362, doi: 10.2337/dc07-1276, indexed in Pubmed: 17977935.

17. Schretlen DJ, Inscore AB, Vannorsdall TD, et al. Serum uric acid and brain ischemia in normal elderly adults. Neurology. 2007;
69(14): 1418-1423, doi: 10.1212/01.wnl.0000277468.10236.f1, indexed in Pubmed: 17909154.

18. Lehto S, Niskanen L, Rönnemaa T, et al. Serum uric acid is a strong predictor of stroke in patients with non-insulin-dependent diabetes mellitus. Stroke. 1998; 29(3): 635-639, indexed in Pubmed: 9506605.

19. Yu KH, Kuo CF, Luo SF, et al. Risk of end-stage renal disease associated with gout: a nationwide population study. Arthritis Res Ther. 2012; 14(2): R83, doi: 10.1186/ar3806, indexed in Pubmed: 22513212.

20. Abbott RD, Brand FN, Kannel WB, et al. Gout and coronary heart disease: the Framingham Study. J Clin Epidemiol. 1988; 41(3): 237-242, indexed in Pubmed: 3339376.

21. De Vera MA, Rahman MM, Bhole V, et al. Independent impact of gout on the risk of acute myocardial infarction among elderly women: a population-based study. Ann Rheum Dis. 2010; 69(6): 1162-1164, doi: 10.1136/ard.2009.122770, indexed in Pubmed: 20124358 .

22. Watanabe S, Kang DH, Feng L, et al. Uric acid, hominoid evolution, and the pathogenesis of salt-sensitivity. Hypertension. 2002; 40(3): 355-360, indexed in Pubmed: 12215479.

23. Lin C, Zhang Pu, Xue Y, et al. Link of renal microcirculatory dysfunction to increased coronary microcirculatory resistance in hypertensive patients. Cardiol J. 2017; 24(6): 623-632, doi: 10.5603/CJ.a2017.0074, indexed in Pubmed: 28653312.

24. Krishnan E, Kwoh CK, Schumacher HR, et al. Hyperuricemia and incidence of hypertension among men without metabolic syndrome. Hypertension. 2007; 49(2): 298-303, doi: 10.1161/01. HYP.0000254480.64564.b6, indexed in Pubmed: 17190877.

25. Mellen PB, Bleyer AJ, Erlinger TP, et al. Serum uric acid predicts incident hypertension in a biethnic cohort: the atherosclerosis risk in communities study. Hypertension. 2006; 48(6): 1037-1042, doi: 10.1161/01.HYP.0000249768.26560.66, indexed in Pubmed: 17060502.

26. Furukawa S, Fujita T, Shimabukuro M, et al. Increased oxidative stress in obesity and its impact on metabolic syndrome. J Clin Invest. 2004; 114(12): 1752-1761, doi: 10.1172/JCI21625, indexed in Pubmed: 15599400.

27. Fabbrini E, Serafini M, Colic Baric I, et al. Effect of plasma uric acid on antioxidant capacity, oxidative stress, and insulin sensitivity in obese subjects. Diabetes. 2014; 63(3): 976-981, doi: 10.2337/db13-1396, indexed in Pubmed: 24353177.

28. Prasad M, Matteson EL, Herrmann J, et al. Uric acid is associated with inflammation, coronary microvascular dysfunction, and adverse outcomes in postmenopausal women. Hypertension. 2017; 69(2): 236-242, doi: 10.1161/HYPERTENSIONAHA.116.08436, indexed in Pubmed: 27993955.

29. Farquharson C, Butler R, Hill A, et al. Allopurinol improves endothelial dysfunction in chronic heart failure. Circulation. 2002; 106(2): 221-226, doi: 10.1161/01.cir.0000022140.61460.1d, indexed in Pubmed: 12105162.

30. Bickel C, Rupprecht H, Blankenberg S, et al. Serum uric acid as an independent predictor of mortality in patients with angiographically proven coronary artery disease. Am J Cardiol. 2002; 89(1): 12-17, doi: 10.1016/s0002-9149(01)02155-5, indexed in Pubmed: 11779515.

31. Wong KYK, MacWalter RS, Fraser HW, et al. Urate predicts subsequent cardiac death in stroke survivors. Eur Heart J. 2002; 23(10): 788-793, doi: 10.1053/euhj.2001.2970, indexed in Pubmed: 12009718 . 
32. Hare J, Johnson R. Uric acid predicts clinical outcomes in heart failure. Circulation. 2003; 107(15): 1951-1953, doi: 10.1161/01. cir.0000066420.36123.35, indexed in Pubmed: 12707249.

33. Feig DI, Johnson RJ. Hyperuricemia in childhood primary hypertension. Hypertension. 2003; 42(3): 247-252, doi: 10.1161/01. HYP.0000085858.66548.59, indexed in Pubmed: 12900431.

34. Richette P, Doherty M, Pascual E, et al. 2016 updated EULAR evidence-based recommendations for the management of gout. Ann Rheum Dis. 2017; 76(1): 29-42, doi: 10.1136/annrheumdis-2016-209707, indexed in Pubmed: 27457514.

35. Stamp LK, O'Donnell JL, Zhang M, et al. Using allopurinol above the dose based on creatinine clearance is effective and safe in patients with chronic gout, including those with renal impairment. Arthritis Rheum. 2011; 63(2): 412-421, doi: 10.1002/art.30119, indexed in Pubmed: 21279998.

36. Rees F, Jenkins W, Doherty M. Patients with gout adhere to curative treatment if informed appropriately: proof-of-concept observational study. Ann Rheum Dis. 2013; 72(6): 826-830, doi: 10.1136/annrheumdis-2012-201676, indexed in Pubmed: 22679303.

37. Ramasamy SN, Korb-Wells CS, Kannangara DRW, et al. Allopurinol hypersensitivity: a systematic review of all published cases, 1950-2012. Drug Saf. 2013; 36(10): 953-980, doi: 10.1007/ s40264-013-0084-0, indexed in Pubmed: 23873481.

38. Hershfield MS, Callaghan JT, Tassaneeyakul W, et al. Clinical pharmacogenetics implementation consortium guidelines for human leukocyte antigen-B genotype and allopurinol dosing. Clin Pharmacol Ther. 2013; 93(2): 153-158, doi: 10.1038/ /clpt.2012.209, indexed in Pubmed: 23232549.

39. Hande KR, Noone RM, Stone WJ. Severe allopurinol toxicity. Description and guidelines for prevention in patients with renal insufficiency. Am J Med. 1984; 76(1): 47-56, indexed in Pubmed: 6691361.

40. Krishnan E, Pandya BJ, Lingala B, et al. Hyperuricemia and untreated gout are poor prognostic markers among those with a recent acute myocardial infarction. Arthritis Res Ther. 2012; 14(1): R10, doi: 10.1186/ar3684, indexed in Pubmed: 22251426.

41. Bos MJ, Koudstaal PJ, Hofman A, et al. Uric acid is a risk factor for myocardial infarction and stroke: the Rotterdam study. Stroke. 2006; 37(6): 1503-1507, doi: 10.1161/01.STR.0000221716.55088.d4, indexed in Pubmed: 16675740.

42. Ndrepepa G, Braun S, Haase HU, et al. Prognostic value of uric acid in patients with acute coronary syndromes. Am J Cardiol. 2012; 109(9): 1260-1265, doi: 10.1016/j.amjcard.2011.12.018, indexed in Pubmed: 22325088. 